giá trị 3,16 cho giá trị dự đoán giãn lớn tĩnh mạch thực quản với độ nhạy 79,07\%, độ đặc hiệu $68,75 \%$ và diện tích dưới đường cong là 0,738 . Nghiên cứu của Kraja $B$ cho rằng tại FIB-4 $=3,23$ có khả năng dự đoán giãn tĩnh mạch thực quản với độ nhạy $72 \%$, độ đặc hiệu $58 \%$, và AUC 0,66 [5]. Trong nghiên cứu của Hà Vũ trên bênh nhân xơ gan nói chung thì điểm cắt dự đoán giãn tĩnh mach thực quản cao hơn - tại cut-off 7,065 cho độ nhạy 98,5\%, độ đặc hiệu $71,1 \%$ [2]. Đối với SAAG, trong nghiên cứu của chúng tôi nhận thấy rằng khả năng dự đoán tối ưu hơn với tại giá trị điểm cắt là 1,9 có độ nhạ $88,37 \%$, độ đặc hiệu $75,87 \%$ và AUC đến 0,902 . Đối với điểm Child-Pugh-đây là một thang điểm (bao gồm cả lâm sàng và cânn lâm sàng) đánh giá độ nặng của bệnh gan tuy nhiên giá trị tương quan và dự đoán giãn tĩnh mạch theo thống kê tính được không cao bằng SAAG và FIB-4. Nghiên cứu của Sayyed về SAAG và APRI ở bênh nhân có bệnh gan mạn đã cho thấy rằng SAAG càng lớn phối hợp với APRI càng thấp là một chỉ số không xâm lấn hữu ích trong dự đoán giãn tĩnh mach thực quản với độ nhạ lển đên $94 \%$ (tính riêng đồ nhay của SAAG là $77,6 \%$ và APRI là $74,1 \%$ ) từ đó có lợi cho xác định sớm bệnh nhân cần chuyển cho phòng nội soi [4]. Từ các nghiên cứu và các nhận định trên rút ra rằng việc sử dụng 2 thông số SAAG và FIB-4 hoặc sử dụng kết hợp cả hai có thể làm tăng độ tin cậy trong việc dự đoán giãn tĩnh mach thực quản ở những bệnh nhân xơ gan đặc biệt đối với nhóm có nguy cơ cao như xơ gan cổ chướng. Điều này có thể vừa giúp làm giảm chi phí và sự khó chịu cho những bệnh nhân xơ gan cổ chướng vừa làm giảm gánh nặng cho các đơn vị nội soi.

\section{KẾT LUÂN}

Trong các thang điểm, điểm Child-Pugh đánh giá độ nặng của gan, tuy nhiên giá trị tương quan và dự đoán giãn tĩnh mạch thực quản không cao. SAAG và FIB-4 là 2 thông số không xâm lấn với độ nhạy cao (lần lượt là $88,37 \%$ và $79,07 \%$ ) để dự đoán giãn tĩnh mạch thực quản ở bệnh nhân xớ gan cổ chướng và do đó có ích trong việc xác định bênh nhân cần chuyển đến những cơ sở điều trị có thể can thiệp nội soi.

\section{TÀI LIÊU THAM KHẢO}

1. Murphy S.L, Xu J, Kochanek K.D, et al. Mortality in the United States, 2017. NCHS Data Brief 2018, 328:1-8. 5

2. Hà Vũ, Bùi Hữu Hoàng. Giá trị của chỉ số $A P R I$ và FIB-4 trong tiên đoán giãn tĩnh mach thực quản ở bênh nhân xơ gan. Tap chí Y Hoc Thành phố Hồ Chí Minh 2015; 19(1):97-102. 3

3. Vũ Bích Thảo, Trân Ngoc Ánh. Giá trị chẩn đoán của độ chênh Albumin huyết thanh và dịch màng bụng trong chẩn đoán phân biệt cổ trướng do xơ gan với các nguyên nhân khác. Tap chi Nghiên cứu Y học 2013; 82(2): 44-48.

4. Sayyed J, Sharma D, Choudhary $K$, et al. A Study on Correlation between SAAG and Platelet Count: Spleen Size Ratio for the Prediction of Esophageal Varices among Chronic Liver Disease Patients. Indian Journal of Basic and Applied Medical Research 2015, 7 (3): 502 - 508.

5. Kraja B, Mone I, Akshija I, et al. Predictors of esophageal varices and first variceal bleeding in liver cirrhosis patients. World J Gastroenterol 2017, 23 (26): 4806-4814.

\title{
ĐÁNH GIÁ THỰC TRẠNG BỆNH LÝ TRÀO NGƯỢC DẠ DÀY THỰC QUẢN KHÁNG TRI VÀ NHU CẦU SỬ DỤNG ỨNG DUNG DI ĐộNG NHẰM HỖ TRỢ QUẢN LÝ BÊ̂NH
}

\author{
Đào Việt Hằng1,2, Trần Thị Ngọc Ánh², Nguyễn Mạnh $\mathrm{Duy}^{2}$
}

\section{TÓM TẮT}

Khảo sát được tiến hành từ tháng 4 đến tháng 8 năm 2020 nhằm đánh giá thực trạng bệnh lý trào ngược dạ dày- thực quản (GERD) kháng trị trong thực hành lâm sàng và nhu câu sử dụng ứng dụng di động

\footnotetext{
${ }^{1}$ Trường Đai họ Y Hà Nọi

2Viên Nghiên cứu và Đào tao Tiêu hóa, Gan mật Chịu trách nhiệm chính: Đào Việt Hằng

Email: daoviethang@hmu.edu.vn

Ngày nhân bài: 22.12.2020

Ngày phản biên khoa hoc: 22.01.2021

Ngày duyệt bài: 1.2 .2021
}

(ƯDDĐ) hỗ trợ quản lý bệnh. Có 101 bác sỹ đã tham gia nghiên cứu, trong đó $97 \%$ bác sỹ đã từng điều tri cho bệnh nhân trào ngược da dày- thực quản, $88 \%$ bác sỹ đã từng găp bênh nhẩn không đáp ứng điều trị. $71,7 \%$ các bác sỹ ghi nhận tỷ lệ bệnh nhân không đáp ứng điêuu trị trong thực tế $\geq 10 \%$. Phối hợp thêm thuốc, tăng liều hay thay đổi thuốc PPI là những xử trí phổ biến của các bác sỹ khi điều trị cho bệnh nhân GERD kháng trị. $100 \%$ bác sỹ đồng ý với việc xây dưng môt ƯDDĐ quản lý bênh trào ngược da dày-thực quản cho bệnh nhân. Tính năng các bác sỹ mong muốn xây dựng trong ƯDDĐ bao gồm hướng dấn về chế độ ăn uống, sinh hoạt, cung cấp kiến thức về bênh và là kênh tương tác giữa bác sỹ và bênh nhân. 
Tư khóa: trào ngược dạ dày thực quản (GERD), kháng trị, ứng dụng di động, thông tin y tế.

\section{SUMMARY}

\section{CURRENT STATUS OF REFRACTORYGASTROESOPHAGEAL REFLUX DISEASEAND THE DEMAND FOR BUILDING MOBILE APPLICATION TO SUPPORT FOR MANAGEMENT}

The survey was conducted from 4/2020 to 8/2020 to assess the current situation of refractory gastroesophageal reflux disease (GERD) and the need of using a mobile application (app) to support patients in GERD management. 101 doctors mainly from the internal medicine department in hospitals participated in the study, $97 \%$ of them have ever treated patients having gastroesophageal reflux disease, $88 \%$ of doctors have ever met patients who had refractory GERD. $71,7 \%$ of doctors reported the rate of refractory GERD in clinical practice is $\geq 10 \%$. $100 \%$ of doctors agreed to develop a mobile application for GERD management. Combining with other medications, increasing the dose or switching to another PPI are the most common strategies for refractory GERD patients. The features that the doctors recommended for the app areinstructions on diet, daily activities, providing information about GERD, and buildingan interactive channel between doctors and patients.

Keywords: gastroesophageal reflux disease (GERD), refractory GERD, mobile application, health information.

\section{I. ĐĂT VẤN ĐỀ}

Bệnh trào ngược da dày thực quản (GERD) là tình trạng các chất trong dịch da dày trào ngược lên thực quản và gây ra các triệu chứng khó chịu có hoặc không kèm biến chứng. Nếu không được chẩn đoán và điều trị, bệnh có thể gây ra các biến chứng nghiêm trọng như viêm loét thực quản, barrett thực quản, đồng thời tăng nguy cơ ung thư thực quản. Tỷ lệ mắc GERD chung trên toàn thế giới chiếm khoảng $13 \%$, cao nhất ở Nam Á và Đông Nam châu Âu, và $7,4 \%$ ở khu vực Đông Nam A[5].

GERD kháng trị được định nghĩa là khi bệnh nhân đã sử dưng thuốc ức chế bơm proton (PPI) liều tiêu chuẩn trong 8 tuần nhưng không đáp ứng [6]. Nguyên nhân dẫn đến tình trạng GERD kháng trị bao gồm bệnh nhân không tuân thủ việc dùng thuốc, không có chế độ ăn uống sinh hoạt phù hợp hoăc do trào ngược dịch không acid hoặc có một số yếu tố nguy cơ khác kèm theo như thoát vị hoành, béo phì [6]. Một nguyên nhân phổ biến khiến bệnh nhân không tuân thủ điêu trị được ghi nhận làdo có sự thuyên giảm triệu chứng sau 1-2 tuần[7]. Do vậy việc đánh giá tình trạng không đáp ứng với điêuu trị GERD cần xem xét tới nhiều yếu tố như việc tuân thủ điêu trị (uống đủ liều thuốc, theo hướng dẫn với từng loại thuốc), chế độ ăn uống, sinh hoạt hoặc các yếu tố nguy cơ kèm theo. Tối ưu hóa điều trị sẽ bắt đầu từ việc đánh giá các nguyên nhân này trước khi tăng liều hoặc phối hợp thuốc[6]. Có đến $45 \%$ bệnh nhân GERD không đáp ứng với điều trị và cần sự tư vấn hỗ trợ can thiệp của các bác sỹ[8]. Tuy nhiên, tại Việt Nam, tỷ lệ bác sỹ trên bệnh nhân còn thấp với 0,76 bác sỹ/1000 dân vì vậy thời gian bệnh nhân được tư vấn về chế độ sinh hoạt, ăn uống trong quá trình uống thuốc có thể bi ảnh hưởngcũng như việc bác sĩ ghi nhận đầy đủ các yếu tố nguy cơ có thể gặp nhiều khó khăn[1].

Thực hiện quyết định về việc tăng cường ứng dụng công nghệ thông tin vào y tế của Bộ Y tế, việc xây dựng ứng dụng di động (ƯDDĐ) trong y tế là một xu hướng mới, tiềm năng có thể hỗ trợ các bác sỹ trong việc tư vấn và theo dõi bênh nhân trong quá trình điều trị[2]. Trên thế giới, đã có nhiều ƯDDĐ được xây dựng và phát triển nhằm hỗ trợ bệnh nhân đặc biệt nhóm bệnh nhân mắc các bênh lý man tính cần theo dõi triệu chứng hoặc hỗ trợ tư vấn chế độ ăn uống sinh hoạt. Vì vậy, chúng tôi tiến hành nghiên cứu này với 2 mục tiêu: Đánh giá thực trạng bệnh lý GERD kháng trị trong thực hành lầm sàng và khảo sát nhu cầu sư dụng U'DDĐ hỗ trợ quản lý bênh GERD.

\section{II. ĐỐI TƯợNG VÀ PHƯƠNG PHÁP NGHIÊN CỨU}

Phương pháp nghiên cứu: Khảo sát sử dụng thiết kế nghiên cứu mô tả cắt ngang, chọn mẫu thuận tiện. Bộ câu hỏi thiết kế trên nền tảng trực tuyển được gửi đến các bác sỹ ở các bệnh viện trên cả nước thông qua chia sẻ trực tuyến. Thời gian mở biểu mấu thu thập số liệ̉u trực tuyến từ 4/2020 đến 8/2020.

Biến số nghiên cứu: Bộ câu hỏi bao gồm 3 phần. Phần thông tin chung gồm các câu hỏi vêđđơn vị công tác, chuyên ngành và kinh nghiêm điêu trị bệnh nhân GERD. Phần khảo sát thực trạng bệnh nhân GERD kháng trị gồm 4 câu hỏi liên quan đến tỷ lệ gặp bệnh nhân GERD kháng trị và các xử trí của các bác sỹ. Phần nhu cầu sử dụng ứng ƯDDĐ bao gồm 2 câu hỏi về các tiêu chí xây dựng ứng dụng. Bộ câu hỏi được thiết kễ bởi nhóm chuyên gia tiêu hóa tại Viện Nghiên cứu và Đào tạo Tiêu hoá, Gan mật và Bệnh viện Đại học Y Hà Nội, sau đó được Hội đồng khoa học Viện Nghiên cứu và Đào tạo Tiêu hoá, Gan Mật thông qua.

Đối tượng nghiên cứu: Các bác sĩ làm việc trong chuyên ngành tiêu hóa, nội soi hoặc nội 
khoa chung tại các bệnh viện trên cả nước đồng ý tham gia khảo sát.

Phương pháp phân tích số liệu: Số liệu được xuất ra và làm sạch bằng phần mềm Microsoft Excel, và phân tích bằng phần mềm SPSS 22.

Đạo đức nghiên cứu: Các bác sỹ tham gia khảo sát được giải thích ý nghĩa, mục đích của khảo sát và tự nguyện đồng ý tham gia trả lời phiếu khảo sát trực tuyến. Các thông tin của người tham gia được bảo mật, chúng tôi không thu thập thông tin định danh đơn vị y tế, bác sĩ hoặc bệnh nhân (tên, địa chỉ, số điện thoại).

\section{KẾT QUẢ NGHIÊN CỨU}

3.1 Thông tin chung về các đối tượng tham gia khảo sát. Bảng 1 cho thấy tổng số có 101 bác sỹ tham gia khảo sát, trong đó chủ yếu là các bác sỹ khoa Nội tiêu hoá $(55.4 \%)$, và các khoa nội chung (34.6\%), chỉ có $10 \%$ là các bác sỹ chuyên khoa khác. Phần lớn các bác sỹ đến từ BV tuyển tỉnh trở lên ngoài ra có dưới $30 \%$ các bác sỹ đến từ bệnh viện tuyến huyện và đơn vị y tế tư nhân hoặc Viện nghiên cứu. Trong số bác sỹ tham gia khảo sát, có đến $96 \%$ bác sỹ đã từng điều trị cho bệnh nhân mắc triệu chứng trào ngược dạ dày-thực quản.

Bảng 1. Bảng thông tin chung về bác sỹ tham gia khảo sát.

\begin{tabular}{|c|c|c|}
\hline Thông tin chung & $\begin{array}{c}\text { Tân số } \\
(n)\end{array}$ & $\begin{array}{l}\text { Tỷ lệ } \\
(\%)\end{array}$ \\
\hline Tống & 101 & 100 \\
\hline Giới tính: & 61 & 60,4 \\
\hline Nữ & 40 & 39,6 \\
\hline \multicolumn{3}{|l|}{ Dơn vị công tác } \\
\hline $\begin{array}{c}\text { Bệnh viện hạng đặc biệt hoặc } \\
\text { tuyến trung ương }\end{array}$ & 37 & 36,6 \\
\hline Bệnh viện tuyến tỉnh & 31 & 30,7 \\
\hline Bệnh viện huyện & 15 & 14,9 \\
\hline $\begin{array}{c}\text { Đơn vị y tế tư nhân (bệnh viện, } \\
\text { phòng khám) }\end{array}$ & 14 & 13,9 \\
\hline Viện nghiên cứu & 2 & 2,0 \\
\hline Khác & 2 & 1.98 \\
\hline \multicolumn{3}{|l|}{ Khoa công tác } \\
\hline $\begin{array}{c}\text { Nội chung hoắc các chuyên khoa } \\
\text { khác hệ nội }\end{array}$ & 35 & 34,6 \\
\hline Nội tiêu hóa & 56 & 55,4 \\
\hline Khác & 10 & 10,0 \\
\hline \multicolumn{3}{|l|}{ Đã điều trị bệnh nhân GERD } \\
\hline Có & 97 & 96,0 \\
\hline Không & 4 & 4,0 \\
\hline
\end{tabular}

3.2 Trải nghiệm của các bác sỹ khi điều trị và tư vấn cho các bệnh nhân có bệnh lý trào ngược dạ dày- thực quản. Kết quả bảng
2 cho thấy trong số 101 bác sỹ tham gia khảo sát có đến 88 bác sỹ đã từng gặp bệnh nhân không đáp ứng điều trị. Theo nhận định của các bác sỹ, tỷ lệ bệnh nhân không đáp ứng điều trị chiếm 10-30\% tổng số bệnh nhân GERD mà họ đã từng tham gia điều trị. Trên $70 \%$ tổng số các bác sỹ nhận định nguyền nhân chính dẫn đến không đáp ứng điều trị là do bệnh nhân không tuân thủ hướng dẫn chế độ ăn uống, sinh hoạt và hướng dẫn uống thuốc. Lựa chọn cách xử trí được nhiều bác sĩ lựa chọn nhất khi gặp bệnh nhẩn không đáp ứng điều trị là phối hợp thêm thuốc, tăng liêu hoặc chuyển loại PPI.

Bảng 2. Thực trạng bệnh nhân được điều trị bởi bác sỹ.

\begin{tabular}{|c|c|c|}
\hline Thông tin chung & $\begin{array}{c}\text { Tần số } \\
\text { (n) }\end{array}$ & $\begin{array}{l}\text { Tỷ lệ } \\
(\%)\end{array}$ \\
\hline \multicolumn{3}{|c|}{$\begin{array}{l}\text { Đã từng gặp bệnh nhân không đáp ứng } \\
\text { đîêu trị }\end{array}$} \\
\hline Có & 88 & 88 \\
\hline Không & 12 & 12 \\
\hline \multicolumn{3}{|c|}{ Tỷ lệ nhóm không đáp ứng điều trị } \\
\hline Dưới $10 \%$ & 26 & 28,3 \\
\hline $10 \%-30 \%$ & 50 & 54,4 \\
\hline $30 \%-50 \%$ & 12 & 13,0 \\
\hline Trên $50 \%$ & 4 & 4,3 \\
\hline
\end{tabular}

\begin{tabular}{|c|c|c|}
\hline \multicolumn{3}{|c|}{ Nguyên nhân dâ̂n đến không đáp ứng đîeu trị } \\
\hline $\begin{array}{c}\text { Không tuân thủ hướng dẫn chế } \\
\text { độ ăn uống, sinh hoạt }\end{array}$ & 86 & 86,0 \\
\hline $\begin{array}{c}\text { Không tuân thủ hướng dần uống } \\
\text { thuốc (thời gian, liều lượng) }\end{array}$ & 69 & 69,0 \\
\hline Tựý sứ dụng thêm các thuốc khác & 39 & 39,0 \\
\hline Mức độ tổn thương nặng & 25 & 25,0 \\
\hline $\begin{array}{c}\text { Trào ngược dịch mật } \\
\text { Có tình trạng thoát vị hoành } \\
\text { kèm theo }\end{array}$ & 26 & 26,0 \\
\hline Yếu tố tâm lí & 47 & 37,0 \\
\hline
\end{tabular}

Xử trí cho bệnh nhân trào ngược không đáp ứng điêu trị

\begin{tabular}{|c|c|c|}
\hline Tăng liều PPI & 41 & 41,4 \\
\hline Chuyển sang loại PPI khác & 44 & 44,4 \\
\hline $\begin{array}{c}\text { Phối hợp thêm thuốc (antacid, } \\
\text { prokinetic v.v...) }\end{array}$ & 69 & 69,7 \\
\hline $\begin{array}{c}\text { Chuyển cho bác sĩ chuyên khoa } \\
\text { Làm thêm các thăm dò khác (vd } \\
\text { đo pH trở kháng 24 giờ) }\end{array}$ & 23 & 23,2 \\
\hline Cân nhắc chỉ định ngoại khoa & 5 & 22,2 \\
\hline Khác & 8 & 8,1 \\
\hline
\end{tabular}

Hình 1 thể hiện các câu hỏi các bác sỹ chuyên khoa nhận được nhiều nhất từ bệnh nhân là chế độ ăn uống (85\%), chế độ sinh hoạt (66\%) và phương pháp điêu trị (64\%). 


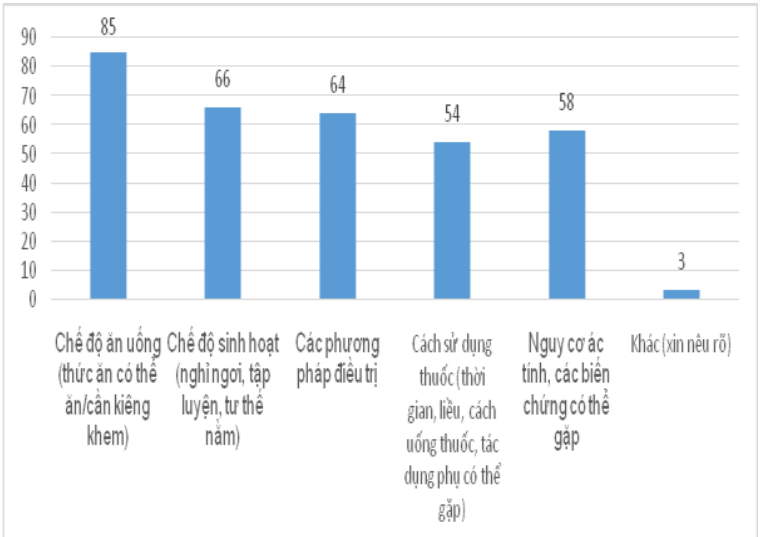

Hình 1. Câu hỏi thường găp từ bệnh nhân. 3.3 Các tiêu chí được các bác sỹ đề xuất nhằm xây dựng ứng dụng.

Hình 2 cho thây hướng dẫn về chế độ ăn uống, sinh hoạt, cung cấp thông tin về kiến thức cho người bệnh được bác sỹ gợi ý nhiều nhất. Ngoài ra, các bác sỹ cũng gợi ý xây dựng một chức năng của ứng dụng như kênh tương tác giữa bác sỹ- bệnh nhân.

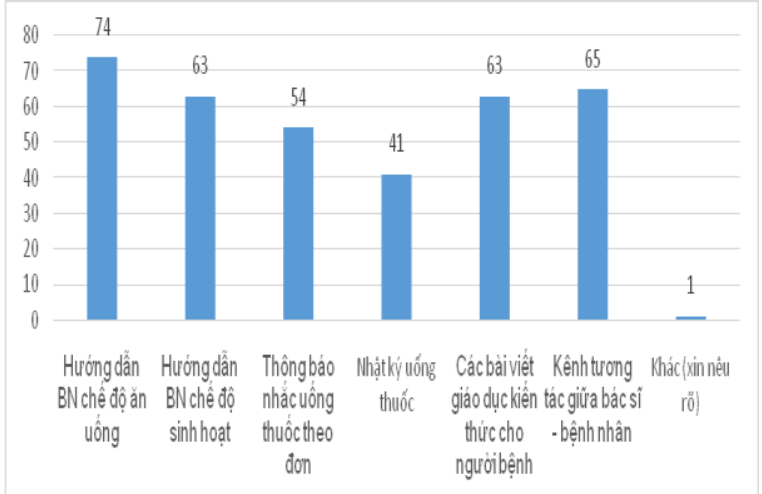

Hình 2. Tính năng bác sỹ mong muốn ở ứng dụng

\section{BÀN LUÂN}

Sự phát triển của công nghệ thông tin đã hỗ trợ cho bệnh nhân cũng như các bác sỹ trên thế giới trong quá trình điều trị và quản lý bệnh lý mạn tính. Khảo sát được thực hiện đã mô tả thực trạng bệnh nhân GERD không đáp ứng điều trị ở việt Nam và đánh giá nhu cầu sử dụng ƯDDĐ quản lý GERD và gợi ý các tiêu chí cho xây dựng ứng dụng.

Khảo sát của chúng tôi cũng ghi nhận đa số các bác sĩ nội tiêu hoá tham gia trả lời đều đã gặp từng các bệnh nhân GERD không đáp ứng điêuu trị với $71,7 \%$ bác sĩ ghi nhận tỷ lệ này $\geq 10 \%$ trong đó $54,4 \%$ bác sĩ lựa chọn tỉ lệ gặp trong thực tế là $10-30 \%$. Tỷ lệnày gần tương tự với một nghiên cứu tổng quan trước đây thu thập kết quả của 19 nghiên cứu cho thấy $45 \%$ bệnh nhân GERD không đáp ứng điêu trị [8]. Theo khuyến cáo của Hội Tiêu hoá Hoa Kỳ đối với bênh nhân GERD kháng trị cần phải tối ưu hóa điêu trị bằng cách chuyển thuốc, phối hợp thuốc, tăng liều điều trị. Tuy nhiên, điều quan trọng là cần xác định bệnh nhân có thật sự tuân thủ điều trị. Khảo sát của chúng tôi cho thấy nguyên nhân của GERD kháng trị ở các bệnh nhân các bác sỹ tìm thấy khi thăm khám bệnh nhân có sự tham gia của các yếu tố liên quan đến tuân thủ và ăn uống sinh hoạt và do không tuân thủ chế độ ăn uống, sinh hoạt, và uống thuốc không đúng theo hướng dẫn (thời gian, liều lượng). Những nguyên nhân này đã được trình bày tương tự ở một nghiên cứu đã được tiến hành tại Mỹ[9]. Bên cạnh đó, câu hỏi bác sỹ gặp nhiều nhất từ bệnh nhân cũng là về chế độ ăn uống, sinh hoạt và phương pháp điều trị. Tuy nhiên, trên thực tế các bác sỹ lại lựa chọn ngay việc điều chỉnh thuốc, cụ thể là phối hợp thêm thuốc, tăng liều PPI hoặc thay đổi thuốc. Hiện nay, ở Việt Nam cũng đã có nhiều dữ liệu liển quan đến các thăm dò trong GERD kháng trị nhu đo $\mathrm{pH}$ trở kháng 24 giờ, đo áp lực và nhu động thực quản độ phân giải caođể loại trừ một số bệnh lý rối loạn nhu động thực quản có triệu chứng tương tự $[3,4]$. Kết quả cho thấy trong số các bệnh nhân kháng trị chỉ có $56,7 \%$ các trường hợp thật sự là GERD bệnh lý[4]. Điều này cho thấy có khoảng cách trong việc xử trí trong thực hành lâm sàng cả về khía cạnh chẩn đoán và tối ưu hóa điều trị.

Trong khảo sát của chúng tôi, 100\% bác sỹ tham gia trả lời đã đồng ý với ý tưởng xây dựng U'DDĐ hỗ trợ bệnh nhân GERD nhằm đảm bảo điều trị hiệu quả. Hiện nay, trên thế giới, nhiều ƯDDĐ về quản lý GERD cũng đã được phát triển và đưa vào sử dụng như Heartburn, Refluxlog, Reflux Tracker, GERD Relief Aid ở Mỹ và các nước châu Âu. Các ứng dụng này cũng nhận được nhiều phản hồi tích cực của bác sỹ và bệnh nhẩn do tập trung vào một số khía cạnh như theo dõi triệu chứng trong quá trình điều trị, đánh giá chẩt lượng cuộc sống, tư vấn về chế độ ăn uống và sinh hoạt. Tuy nhiên, tại Việt Nam chưa có dữ liệu về nhu cầu xây dựng ỬDĐ về quản lý GERD của bác sĩ điều trị để có tiền đề cụ thể xây dựng các chức năng phù hợp. Khảo sát của chúng tôi cho thấy các hướng dẩn chế độ ăn uống và sinh hoạt cho bệnh nhân mắc GERD đồng thời cung cấp các bài viết và thông tin về bênh là những chức năng được các bác sỹ gợi ý nhiều nhất để xây dựng ƯDDĐ๋. Những gợi ý này 
phù hợp với kết quả về những câu hỏi mà các bác sỹ thường gặp ở các bệnh nhân GERD. Ngoài ra, các bác sỹ cũng kỳ vọng đây sẽ là một kênh tương tác giữa bác sỹ và bệnh nhân từ đó đảm bảo bệnh nhân được tối ưu hóa trong tư vấn và theo dõi điều trị.

Đây là khảo sát bước đầu với số lượng bác sỹ tham gia còn hạn chế. Tuy nhiên, khảo sát cũng đã cung cấp cái nhìn ban đầu về thực trạng và nhu cầu sử dụng ƯDDĐnhằm hỗ trợ quản lý dạ dày-thực quản, là tiền đề cho các nghiên cứu tiếp theo nhằm làm rõ hơn nhu cầu thực tế trong sử dụng ứng dụng.

\section{KẾT LUÂ̂N}

Tỷ lệ các bác sỹ từng điều trị cho bệnh nhân GERD chiếm đến $98 \%$ tổng số bác sỹ tham gia khảo sát, $88 \%$ bác sỹ đã từng gặp bệnh nhân GERD kháng trị. $100 \%$ bác sỹ đồng ý xây dựng một U'DDĐđể hỗ trợ quản lý GERD. Bên cạnh đó, ứng dụng hỗ trợ quản lý trào ngược dạ dàythực quản sẽ là một hướng đi đầy hứa hẹn giúp nâng cao chất lượng điều trị cho bệnh nhân.

\section{TÀI LIẸU THAM KHẢO}

1. Tổ chức $\mathbf{Y}$ tế thế giới, Tổng quan quốc gia về Nhân lực y, tế Việt Nam 2018.

2. Bộ Y Tuế. Ứng dụng công nghệ thông tin hướng tới xây dựng nền y tế thông minh. 2019; Available from: https://moh.gov.vn/chuong-trinh-muc-tieuquoc-gia/ /asset_publisher/ 7ng11fEWgASC/ content/ung-dung-cong-nghe-thong-tin-huong-toixay-dung-nen-y-te-thong-minh.

3. Đặng Thị Lõn, et al., Hình thái vùng nối dạ dày thự̛c quản và ap lực cơ thắt thực quản dưới bằng kỹ thuât HRM ở bệnh nhân có thooát vị hoành trượt trên nội soi. Tạp chí Y Dược học Lẩm sàng 108 2020. 15(2).

4. Đào Việt Hằng and Hoàng Bảo Long, Bước đầu đánh giá kết quả đo $\mathrm{pH}$-trở kháng 24 giờ ở bênh nhân trào ngược da dày-thức quản kháng tri. Tạp chí nghiên cứu Ý học, 2019. 119(3): p. 33-40.

5. Vakil, N., et al., The Montreal definition and classification of gastroesophageal reflux disease: a global evidence-based consensus. Am J Gastroenterol, 2006. 101(8): p. 1900-20; quiz 1943.

6. Fock, K.M., et al., Asia-Pacific consensus on the management of gastro-oesophageal reflux disease: an update focusing on refractory reflux disease and Barrett's oesophagus. Gut, 2016. 65(9): p. 1402-15.

7. Mermelstein, J., A. Chait Mermelstein, and M.M. Chait, Proton pump inhibitor-refractory gastroesophageal reflux disease: challenges and solutions. Clin Exp Gastroenterol, 2018. 11: p. 119-134.

8. El-Serag, H., A. Becher, and R. Jones, Systematic review: persistent reflux symptoms on proton pump inhibitor therapy in primary care and community studies. Aliment Pharmacol Ther, 2010. 32(6): p. 720-37.

9. Mermelstein, J., A.C. Mermelstein, and M.M. Chait, Proton pump inhibitors for the treatment of patients with erosive esophagitis and gastroesophageal reflux disease: current evidence and safety of dexlansoprazole. Clin Exp Gastroenterol, 2016. 9: p. 163-72.

\section{ĐÁNH GIÁ KẾT QUẢ ĐO NHÃN ÁP BẰNG VỚI MộT SỐ LOẠI NHÃN ÁP KẾ}

\section{Đỗ Tấn ${ }^{1}$, Phạm Thị Thu Thủy ${ }^{2}$, Hoàng Thị lành ${ }^{3}$}

\section{TÓM TẮT}

Mục tiêu: Đánh kết quả đo nhãn áp (NA) bằng nhãn áp kế (NAK) Maclakov, NAK Goldmann và NAK không tiếp xúc. Đối tượng và phương pháp nghiên cứu: Nghiên cứu mô tả cắt ngang trên 702 mắt của 352 bệnh nhân khám và điều trị tại khoa Glôcôm Bệnh viện Mắt Trung ương từ tháng 11/2017 đến tháng 8/2018. Kết quả: Tuổi trung bình của nhóm bệnh nhân trong nghiên cứu là 56,06 $\pm 16,88$ (khoảng, 15 đến 90 ). Nhóm tuổi từ 60 - $\leq 80$ có tý lệ

${ }^{1}$ Bệnh Viện Mắt Trung Ương

Đại Học Y Hà Nọi

${ }^{3}$ Bềnh Viện Thanh Nhàn

Chịu trách nhiệm chính: Đỗ Tấn

Email: dotan20042005@yahoo.com

Ngày nhận bài: 18.12.2020

Ngày phản biện khoa họ: 25.01.2021

Ngày duyệt bài: 2.2.2021 cao nhất chiếm 42,3\%. Bênh nhân nữ chiếm tỷ lệ cao hơn (55,4\%). Trong số bệnh nhân nghiên cứu, glôcôm chiếm tỷ lệ cao nhất 42,5\%. Với kết quả đo của cả ba loại NAK, các mắt nhóm glôcôm có NA trung bình cao nhất, các mắt bong võng mac có NA trung bình thấp nhất. Với NAK Maclakov, nhóm có NA trong khoảng từ 16 đến $21 \mathrm{mmHg}$ chiếm tỷ lề cao nhất $(74,1 \%)$, các mắt có $\mathrm{NA}$ rất cao $\geq 32 \mathrm{mmHg}$ có tỷ lệ thấp nhất 2,6\%. Chênh lệch chỉ số $N A$ của NAK Maclakov và NAK Goldmann với từng mức NA là: NA thấp < $16 \mathrm{mmHg}: 2,397 \pm 1,248 \mathrm{mmHg}$; Bình thường 16 - 21mmHg: 2,604 $\pm 1,563 \mathrm{mmHg}$; Bình thường cao 22 - 25mmHg: 1,100 $\pm 3,460 \mathrm{mmHg}$; Cao $26-31$ mmHg: $-2,043 \pm 3,989 \mathrm{mmHg}$; Rất cao $\geq 32 \mathrm{mmHg}$ : $3,611 \pm 4,667 \mathrm{mmHg}$. Chênh lệch chỉ số NA của NAK Maclakov và NAK không tiếp xúc với từng mức NA là: $\mathrm{NA}$ thấp < 16mmHg: $3,687 \pm 2,741 \mathrm{mmHg}$; Bình thường 16-21mmHg: 2,270 $\pm 3,070 \mathrm{mmHg}$; Bình thường cao $22-25 \mathrm{mmHg}:-0,536 \pm 4,960 \mathrm{mmHg}$; Cao $26-31 \mathrm{mmHg}:-3,207 \pm 5,932 \mathrm{mmHg}$; Rất cao $\geq$ 32 mmHg: $-3,883 \pm 4,913$ mmHg. Kết luận: Kết quả 